$1-1-1983$

\title{
Characteristics of rural residents in West Virginia : results of a 1981 survey in nine counties
}

Dale Colyer

Follow this and additional works at: https://researchrepository.wvu.edu/ wv_agricultural_and_forestry_experiment_station_bulletins

\section{Digital Commons Citation}

Colyer, Dale, "Characteristics of rural residents in West Virginia : results of a 1981 survey in nine counties" (1983). West Virginia Agricultural and Forestry Experiment Station Bulletins. 683.

https://researchrepository.wvu.edu/wv_agricultural_and_forestry_experiment_station_bulletins/577 


\section{Characteristics of Rural Residents \\ in West Virginia}

Results of a 1981 Survey in Nine Counties

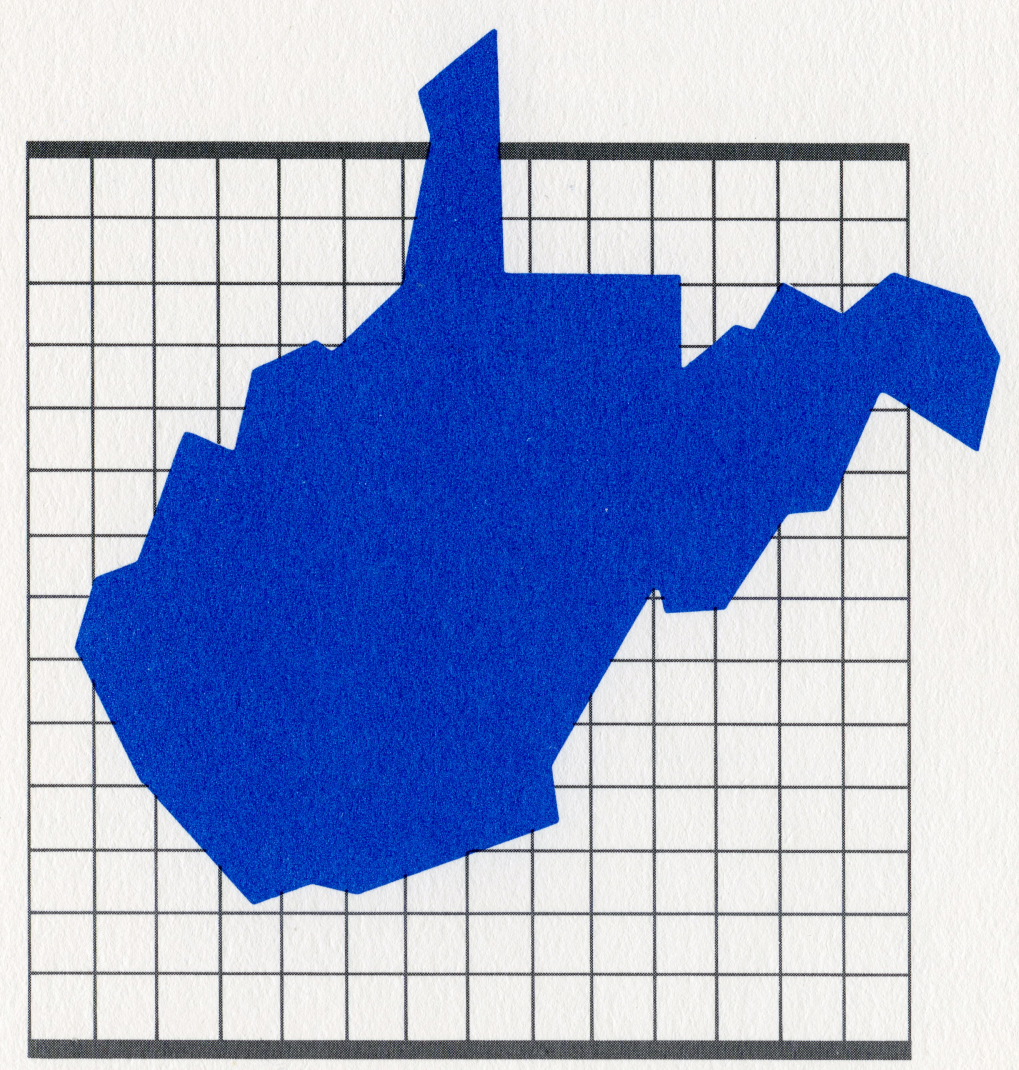

Bulletin $683 \square$

$\square$ May 1983

West Virginia University

Agricultural and Forestry Experiment Station 


\section{Authors}

Dale Colyer is agricultural economist and chairman, and Dennis Smith is associate agricultural economist, Division of Resource Management. Anthony Ferrise is State Extension SpecialistPlanning and Development, Center for Extension and Continuing Education; Edwin Akamonu was graduate student in agricultural economics.

\begin{tabular}{lr}
\hline Contents & 1 \\
\hline Introduction & 1 \\
\hline Procedures & 2 \\
\hline Survey Results & 2 \\
\hline Location & 3 \\
\hline Characteristics of Places & 3 \\
\hline Characteristics of Households & 4 \\
\hline Production Activities & 4 \\
\hline Migration Variables & 5 \\
\hline Commuting & 6 \\
\hline Community Problems & 6 \\
\hline Information and Credit & 6 \\
\hline Services Satisfaction & 7 \\
\hline Socio-Economic Factors & 7 \\
\hline Characteristics of Places & 8 \\
\hline Household Characteristics & 8 \\
\hline Services Satisfaction & 9 \\
\hline Migration Relationships & 9 \\
\hline Characteristics of Places & 9 \\
\hline Household Characteristics & 10 \\
\hline Services Satisfaction & 10 \\
\hline Conclusions & 12 \\
\hline Tables I-VIII & \\
\hline &
\end{tabular}

West Virginia University

Agricultural and Forestry Experiment Station College of Agriculture and Forestry

Dale W. Zinn, Director

Morgantown 


\section{Characteristics of \\ Rural Residents in West Virginia: \\ Results of a 1981 Survey in Nine Counties}

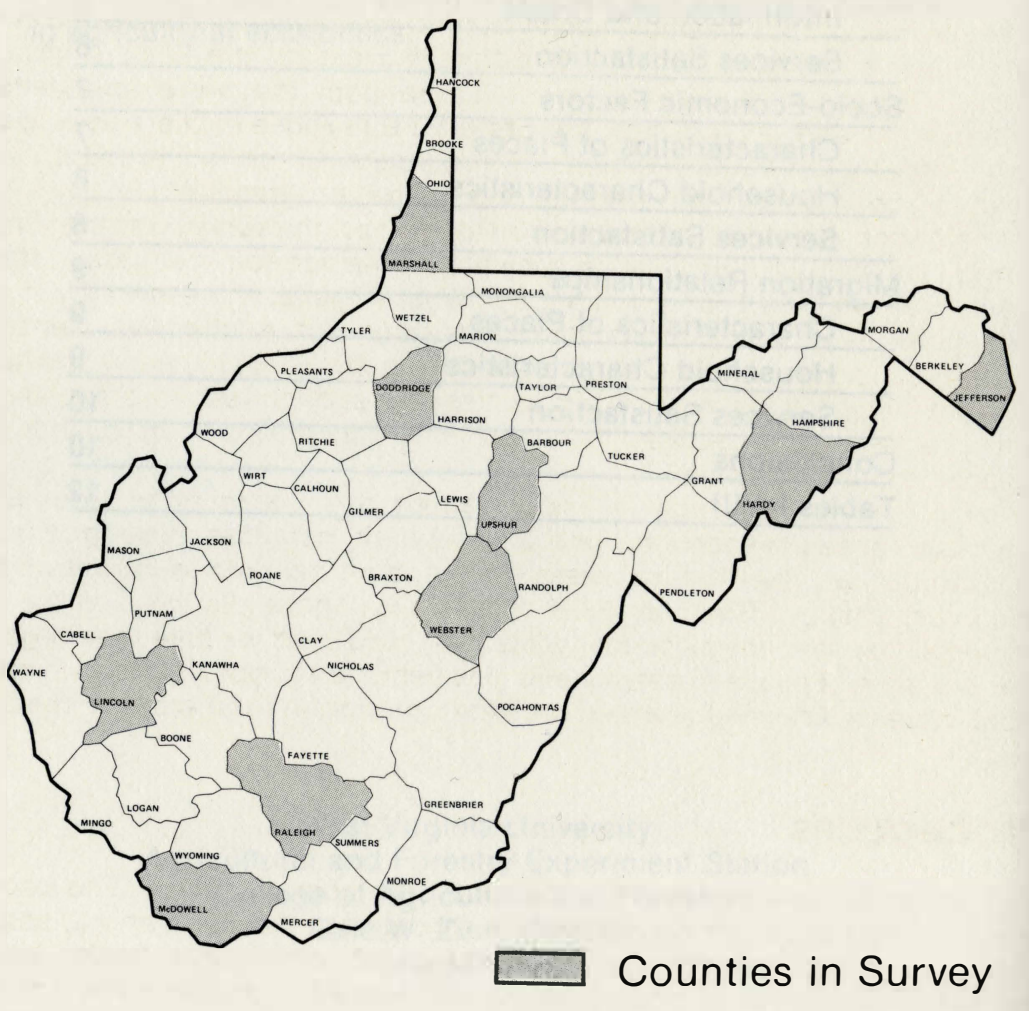

Figure 1. Location of Counties in the Rural Development Survey.
Dale Colyer, Dennis Smith, Anthony Ferrise, and Edwin Akamonu

\section{Introduction}

In the summer of 1981 a sample survey of rural residents was conducted in nine West Virginia counties, located in different areas of the State (Figure 1). Although the counties were not selected at random, they were representative of their areas and, as a group, the State. The purpose of the survey was to obtain information about residents of rural areas-information that might be useful in public policy, educational, and related programs.

A major consideration in the decision to conduct the survey was the reversa of long-term trends in population growth and the economic situation of rural areas. Prior to about 1968, population in West Virginia, and especially in most of its rural areas, had been declining steadily. But, as the 1980 Census of Population confirmed, population grew during the 1970s in nearly all areas in the State including the more rural counties. The economies of most rural areas have changed from declining to expanding and problems of growth have replaced those of decline.

However, relatively little is known about the residents in rural areas, especially those who account for the population increases. It was not known, for example, whether the increases were due primarily to in-migration or to less out-migration. Similarly little was known about the jobs of the rura residents, the land they occupy, what they produced, or how they regarded their situation. Thus, a questionnaire was designed to obtain information that could increase knowledge about the new situation in rural areas of the State.

\section{Procedures}

Nine counties were selected for the rural development survey. The counties were selected to obtain representation throughout the State and to assure a wide variety with respect to the importance of economic activities such as agriculture and mining, income levels, and related characteristics. Thus, the counties were not random ly selected and the results can not be generalized for the State in a statistical sense.

Personal interviews were used to obtain information from a random sample of persons in unincorporated areas of each county. Within each county, a rura residence near the starting point of each day's interviewing was selected at random and then each tenth to twentieth house, depending on the density of 
the rural population, was selected for interviewing. The interviewing routes were selected to assure county-wide coverage. The interviews were conducted by West Virginia University students, except for one county where local school teachers were hired.

A questionnaire was used to obtain information about the socio-economic characteristics of the rural residents, the places where they live, data on migration (moving), production activities, problems, needs, and attitudes. A portion of the questionnaire was concerned with measuring satisfaction with 26 services. Respondents rated each service on a scale of one (1) for very satisfied, to five (5) for very dissatisfied. In the analyses these scores were used as both categories to classify responses and as cardinal measures to quantify responses, i.e., to obtain average scores for the sample and subgroups within the sample. In this scale, higher average scores indicate less satisfaction, with a score of more than three representing relatively greater dissatisfaction.

A variety of descriptive and statistical procedures were used to analyze the results. These included means and counts classified in various ways, Chisquare analyses, analysis of variance, Duncan's multiple range tests, and regression analyses. The combination of procedures allows determination of significant relationships and the quantitative or directional nature of the relationships.

\section{Survey Results}

A total of 2,752 persons in the 967 households were surveyed (average of 2.85 persons per household). In addition to socio-economic information about the household, data were collected about the places the residences were located, about production activities carried out on the places, work related information, satisfaction with services, information needs, sources of information, and credit. Results are reported by county, area, and factors associated with variability.

Several factors can influence or be associated with variations in the characteristics and attitudes of people. Among these are location, socioeconomic characteristics, and migration variables. A number of different variables for each of these three broad categories were used to analyze the results to determine the interrelationships that exist among them. The results of this analysis provide useful information for those who provide services or are involved in making decisions for rural areas. A variety of information is provided since not everyone wants or needs the same data.

\section{Location}

The primary location variables are county and area of the State. The survey included nine counties located in the Northern and Eastern Panhandles, central, and southern areas of the State. There were significant differences in nearly all of the characteristics when computed as county averages, although some characteristics tended to be similar in some of the counties (Tables I-VIII).

Counties located in a general area tended to be similar. Those in the southern coal-producing area, for example, generally had similar characteristics. Although similar, there were differences among those counties located relatively close to one another. Webster County, for example, located in central West Virginia, frequently tended to be similar in characteristics to the southern counties. The more important similarities and differences will be discussed in the following sections.

\section{Characteristics of Places}

The average size of places va ried from 182 acres in Hardy County to 8 acres in Raleigh County. The sizes were larger in Jefferson and Doddridge counties where farming is more preval ent. More than 34 percent of the places were fullor part-time farms in Jefferson County, followed by 26 percent in Hardy, 23 percent in Doddridge, and 18 percent in Upshur. These were places where farm products were produced and sold. There were no full-time farms among the places where intervievvs were conducted in McDowell, Raleigh and Webster counties, but there were a few part-time farms in each county. Webster counties, but the were a few part-time farms in each county. Although no farm products were produced for sale, many other persons considered their places to be "farms." The majority of the places were used primarily for residential purposes in all nine counties, varying from 61 percent in Jefferson County to nearly 97 percent in Webster County.

The average size of place and percentage used for farming tended to be higher in the eastern and central counties (except Webster) and lower in all the Webster County. Marshall is a small county in a relatively heavily populated and industrialized area. The southern counties are characterized by very rough terrain, little level land, coal production as an important enterprise, and relatively concentrated land ownership. Webster County is similar to the southern counties with respect to most of these characteristics. It is one of the most remote and inaccessible counties in the State.

While the general conditions with respect to land ownership vary considerably among these counties, the majority of the rural residents included in the survey own all or a part of the parcel of land where they live. This varied from about 75 percent of the interviewees in Jefferson County to 99 percent in Raleigh County - overall, about 88 percent owned some land. Nonowners generally rented the places where they lived although a few had other arrangements including free use of the property or life estates.

\section{Characteristics of Households}

Household characteristics varied substantially from county to county but the distinctions between the southern and other counties were not quite as sharp as with the characteristics of the places. The average size of household varied from a high of 3.6 persons in McDowell county to 2.5 in Hardy County. Most o the other counties were close to the nine-county average of 2.85 persons per household. The age distributions were similar in most counties except that there was a higher proportion of persons less than 18 years of age in McDowell County and a lower proportion over 65 in Raleig in residents of the survey households were born in the county where they now live and the majority of the remainder were born elsewhere in West Virginia. An exception was Jefferson County where only 42 percent were born in the county while 40 percent were born outside of the State. The other panhandle counties (Hardy and Marshall) also had somewhat higher portions born in all areas in all areas consisted of "central families" (husband, wife, and children or husband and wife). Single-person households and mother and children 
households tended to be slightly more common in the southern counties as well as in Webster County.

Sources of income, occupations, and educational levels varied considerably with a north-south pattern fairly common. Income from the sale of farm products was more common from the places in the panhandle and centra counties (except for Webster) than in the more southern counties. Slightly more households received social security and other retirement incomes in Lincoln, McDowell, and Webster counties than in the other six counties. Coal mining was a major source of income for respondent families in Upshur, Webster, Raleigh, and McDowell counties, but not elsewhere, although there is substantial mining in Marshall County and large coal reserves in Lincoln County. Relatively few households reported receiving food stamps or welfare payments as sources of income, although several reported these as income sources in Lincoln, McDowell, and Webster counties. Incomes tended to be highest in Jefferson County, followed by McDowell and Raleigh. People in Jefferson tend to be more highly educated and many may work in the Washington area, while coal mining and related work probably accounts for the higher earnings in Raleigh and McDowell counties. Families in Webster and Lincoln counties tended to have lower incomes. This is probably partly due to location, poor transportation facilities, poorer resource endowments, and, consequently, fewer employment opportunities.

There were substantially more persons with less than a complete high school education in the southern counties than in the other counties. This varied from 203 persons in McDowell and 198 in Webster to only 38 persons in Jefferson County. Lincoln, Raleigh, and Upshur counties also had substantial numbers of adults who had not completed high school. The number with college training was highest in Jefferson County, probably because of a large number of in-migrants (perhaps from the Washington, D.C. area).

\section{Production Activities}

The most common production activity on respondents' places was growing vegetables for home use. This was true for almost one-half of the households in Lincoln County and nearly 80 percent in McDowell. Relatively few households reported producing any products for sale but the more farm-oriented counties, Jefferson and Hardy, followed by Doddridge, Upshur, and Marshall, did have substantial numbers who produced and sold farm products. Beef cattle and dairy products were the most common items produced for sale although poultry, eggs, sheep, corn, fruit, and several other minor crops and livestock were produced and sold by some of the households. A considerable number of respondents in Lincoln County produced and sold tobacco. Many respondents harvested firewood but relatively few sold it.

\section{Migration Variables}

An average of 25 percent of the interviewees stated that they had never moved but this varied from 1.7 percent in Webster County to 53.4 percent in Hardy. There was no apparent north/south pattern among the nine counties with respect to the time when the last move was made. Those who had moved with in the last five years varied from 10 percent in McDowell County to 29.9 percent in Webster, while those who moved between five and ten years ago varied from 5.8 percent in Hardy County to 21 percent in Jefferson.
Most respondents had made their last move from another location within the county of current residence, ranging from 42 percent in Doddridge to 76 percent in McDowell County. About equal numbers had moved from elsewhere in the elsewhere in th Jefferson (6 percent) had lower proportions who had moved from within the State. Jefferson had the largest proportion who had moved from outside the State, 31 percent, while Hardy, McDowell, and Webster each had about 21 percent.

Overall, about equal numbers, 35 and 33 percent respectively, had moved from rural non-farm areas and small towns while about 23 percent had moved f oin farms and 10 percent from urban areas. However, nearly 60 percent of those moving in Marshall County reported having moved from farms while only 2 percent in Raleigh County moved from farms. No one reported having moved from an urban area in Marshall County, but 17.5 and 16.0 reported doing so in Doddridge and Jefferson counties, respectively. Typically, relatively few respondents reported moving from farms in the southern counties, while relatively more had moved from urban areas in the Eastern Panhandle areas.

The more important reasons cited for moving included to change lifestyles, a preference for rural living, followed by a dislike of the previous place, and to obtain employment. Persons from the southern (Raleigh and McDowell) and central counties (Upshur and Webster) were more apt to cite changing lifestyles and dislike of the previous place of residence, whereas those from Jefferson, Lincoln, and Marshall more frequently cited a preference for rura living. Many had moved for various other reasons-marriage, retirement, etc.

Nearly two-thirds of those who had moved reported no change in their incomes as a result of moving and 18 percent reported increases and 15 percent decreases. Relatively more of those who had moved in Doddridge Hardy, Marshall, or Upshur counties reported no changes in their incomes. More movers from Hardy, Upshur, and Webster reported decreases than increases. The average size of increase was $\$ 3,276$ and the average decrease $\$ 5,241$. Several of the income decreases were reported by people who moved to the county after retirement.

\section{Commuting}

More than 600 of the households reported having one or more members who worked off the place, either full or part time. There were 169 households where two or more persons commuted to work (Appendix Table VI). The average one-way distance traveled to work was about 17 miles, with a range of 0.2 to more than 100 miles. The county averages ranged from a high of 25.4 miles in Doddridge to a low of 11.7 in Hardy. About 85 percent of those who indicated the mode of transportation used private autos to get to work. Nearly 10 percent were in car pools, with most of these located in Jefferson and Webster six persons were reported as using some form of transportation.

Three-fourths of the interviewees who commuted to work indicated that they commuted five times per week and one-tenth said they commuted six times pe week. A few commuted only one to four times per week and another smal group worked seven days per week. There were more people commuting less than five days in Webster than in any of the other eight counties. Relatively fewer total persons were reported as commuting in Upshur County. 


\section{Community Problems}

Interviewees were asked to indicate the three most important problems in their communities. A large number of different problems were listed-697 listed at least one problem, 498 at least two, and 317 listed three problems. The most listed problems were roads, a lack of community activities, a lack of services, a lack of employment opportunities, poor public utilities, and inadequate law enforcement. Law enforcement had several related problems which, if combined, would raise the responses to that problem considerably-problems such as vandalism, theft and drugs. Housing, stray dogs, pollution, welfare, land prices, and excessive development were all mentioned more than twenty times each, but few other problems were mentioned as many as ten times.

Roads were the most commonly mentioned problem in all but Dodd Hardy and Lin particular particular counties were public services in Marshall and McDowell, employment opportunities in Upshur and McDowell, a lack of community facilities in Doddridge and Hardy, and public utilities in Raleigh County.

Respondents also were asked about farm production and marketing problems, but relatively few indicated that they had such problems. Some stated that prices were too low and a few cited transportation as a marketing problem. The more frequently mentioned production problems were insects, weather, and labor. These were more apt to be cited by residents of the more agriculturally oriented counties such as Hardy and Jefferson.

\section{Information and Credit}

Many households in the survey indicated that they obtained information from several sources, the most common being the Cooperative Extension Service, followed by Soil Conservation Service, State Department of Agriculture, Farmers Home Administration, and Agricultural Stabilization and Conservation Service.

The most notable feature of the results when evaluated by county was the much greater use of most information sources, and especially the agricultural information, by the rural residents of Jefferson County. That county had the most highly educated group of rural residents, is the most productive agricultural county of the nine, and had the greatest proportion of rura residents who had moved from out-of-state. Upshur followed in the number of respondents who utilized the information sources listed. Fewer McDowell County residents used the information of the agencies listed, while there were relatively few differences in the other counties.

\section{Services Satisfaction}

The county and area where the respondents lived appeared to have a very strong influence on the general level of satisfaction with services. Residents of the southern (primarily coal) counties, except for Raleigh, tended to be less satisfied than those in other parts of the State. Surveyed residents in McDowell County were, on the average, the least satisfied, followed by those in Webster and Lincoln counties. McDowell County respondents were least satisfied with 18 of the 26 services, and those from Webster were least satisfied for the other eight services covered by the survey. Raleigh County, the one exception in the southern part of the State, is the trade center of the coal fields and has had considerably more industrial development than the other counties in that area.
The relatively more satisfied respondents tended to be located in the Northern and Eastern Panhandle counties. Respondents in Doddridge County also were relatively satisfied (or less dissatisfied for those services where dissatisfaction was the more prevalent response). In general, counties with higher average levels of satisfaction were those with higher average incomes higher average levels of satisfaction were and with better, less rough terrains. While the levels of satisfaction were different, it should be noted that there was a fairly general agreement between counties in the way the individual services were rated in relation to each other. Thus, persons in all areas tended to be relatively dissatisfied with road maintenance, but generally were more satisfied with emergency medical and library services.

\section{Socio-Economic Factors}

Income, education, occupation, family situation, and background are among the socio-economic factors that might influence the characteristics or attitudes of the respondents or result in variations in the types of places where they live or uses they make of their property. The impacts of these factors on the characteristics of the rural residents included in the survey are analyzed in the following sections.

\section{Characteristics of Places}

Parcel size and use tended to vary with income and education. In general, larger acreages were associated with higher incomes and more years of education. Those with incomes of more than $\$ 50,000$ had an average of 293 acres and those with incomes between $\$ 30,000$ and $\$ 50,000$ averaged 114 acres. Those with incomes of less than $\$ 5,000$ had places that averaged 36.5 acres and those with incomes of $\$ 5,000$ to $\$ 10,000$ averaged 41.8 acres. Similarly, persons with post-graduate college work had an average of 123.5 acres while those with other college training averaged 111.1 acres. Persons with a grade school or less education lived on places with an average of 22.4 acres while places of those with some high school averaged only 18.4 acres Persons who were high tended to vary with size. Larger-sized parcels tended to be used as farms although many persons with relatively large acreages produced no farm products. Thus, although 253 persons considered their places to be farms, only 134 of these used their land for farm production activities-either on a fullor part-time basis.

Household composition and household size also were related to the characteristics of the places. Composition categories consisted of single person households, husband and wife, husband, wife and children, mother and children, and other combinations. Household composition and household size were related due to the definition of composition. Smaller households tended to be associated with smaller parcels that were used primarily as residences. Use of the parcels as full- or part-time farms tended to increase with household size, although 75 percent or more of the parcels were used primarily as residences for all household sizes.

Single person households tended to have smaller places (an average of 37.6 acres), but the smallest average parcel size was for mother and children (29 acres). The largest average size was for "other" household composition (113.8 acres), husband and wife combinations averaged 70.6 acres, and husband wife and children households averaged 62.3 acres each. 


\section{Household Characteristics}

Lower incomes and educational levels tended to be associated with single person households. Females accounted for two-thirds of the single person households and these tended to have lower incomes-more than one-half of the single females had incomes of less than $\$ 5,000$. The majority of these were relatively elderly. Higher incomes tended to be associated with increased family size, that is, higher proportions of the larger families were in groups with higher incomes. There were 44 percent of the households with three or more family members which had incomes of more than $\$ 20,000$. In contrast, 47 percent of the one person households had incomes of less than $\$ 5,000$ and another 23 percent had incomes between $\$ 5,000$ and $\$ 10,000$. Two person households also tended to be in the three lower income categories (under $\$ 20,000$ ), but only 33 percent of these households had incomes of less than $\$ 10,000$. Many persons in both of these groups consist of elderly persons who are retired. Thus, households composed of single persons and husband-wife combinations tend to be in the lower income categories. Husband-wifechildren household compositions tended to have relatively high proportions in children household compositions tended to have relatively high proportions in the three higher income groups-those over $\$ 20,000$. The majority of the husband-wife-children households, 56 percent, had incomes between $\$ 20,000$ and $\$ 50,000$. Mother-child households tended to be in the lower income groups; 54 percent of them had incomes of less than $\$ 10,000$ and 30 percent were in the less than $\$ 5,000$ income group.

\section{Services Satisfaction}

Socio-economic factors appear to have considerable influence on levels of satisfaction with services. Among the factors tested for relationship to satisfaction were income, education, occupation, household composition, and background of the persons. The analysis indicated that the relationships generally were not linear, with both the lowest and highest income categories tending to be more satisfied than the intermediate groups. The means of the scores for respondents in the under $\$ 5,000$ income group and the over $\$ 50,000$ group were both at the lower end of the scale for 15 of the 26 services and one or the other were at the lower end for 10 out of the 11 remaining services.

Household size and composition were factors affecting satisfaction with services. There were significant differences in satisfaction for family size $(1,2$, $3,4,5$ or more) for 18 of the 26 services. Satisfaction generally decreased as household size increased. Single person households were the most satisfied for 11 of the services, while those with 5 or more persons in the household were the least satisfied for 20 of the services. There was a tendency, although somewhat less pronounced than for size, for respondents from households without children to be more satisfied than for those with children, whether it was a single person household or a husband and wife household. For those households wit whether the hou whether the household was father, mother, and children or mother and children. Other types of households were not prevalent enough to use in the analysis

The other socio-economic factors considered in the analysis-education, occupation and place of birth-were not found to be strongly related to the level of satisfaction.

\section{Migration Relationships}

The variables used to evaluate migration were time when moved, size or type of place moved from, and reason for moving. With rural populations increasing due in part to in-migration, the characteristics of those who are moving into an area may become increasingly important, especially if they are different than persons already residing in the area. This analysis suggests that those who paid they had never moved tend to have a substantially distinct set of said they had never the lived on and owned more land, were more characteristics. Typically this group lomer apt to be farming, tended to have somewhat lower incomes, and had smaller households (one and two person). They also tended to be older and were more likely to be retired.

\section{Characteristics of Places}

People who had moved lived on smaller places and the more recently they had moved the smaller was the average size of parcel where they resided. There were relatively few differences whether they had moved from within the county, from elsewhere in the State, or from outside the State. However, those who had moved from farms tended to live on larger-sized places. About onefourth of those who had never moved used their places as farms while only 8 ourth of those who had never moved used their places as farms while only 8 percent of those who had moved less than five years ago and 14 percent of those who had moved more than five years ago did so. However, larger proportions of all groups considered their places to be farms although producing little or no farm products. Those moving from farms as well as those who had never moved were more likely to be engaged in some type of farming who her not large, those from urban areas were more apt to be farming than persons from small towns or rural non-farm areas.

\section{Household Characteristics}

Slightly larger proportions of those who had moved more than ten years ago and of those who had never moved were in the lower income categories while those who had moved in the last five years had relative concentrations in both the lower and higher income groups. Those who had moved between five and the middle income groups. There was no systematic relationship between education level and time when There was no systematic relationship between education level and time when moved.

Geographic area moved from (within county, elsewhere within State, and out-of-state) were not closely related to income or education, but they were to household size household composition, and type of place moved from. Houn smaller for those who had noved and more were single person or husband-wife compositions. Of those who had move were single person or husband-wife compositions. urban areas. A relatively larger proportion of those who had moved within the last five years also were from out-of-state. About 18.6 percent of the respondents had moved during the last five years, but 30 percent of those who had moved from out-of-state did so in that time period.

The type of place moved from was closely related to income and education. People from farms tended to have fewer years of formal education and to be in the lower income groups while the opposite existed for persons from urban areas. Those from rural non-farm areas and small towns were in intermediate groups, but those from small towns were, on the average, somewhat better 
educated and in higher income groups. The majority of all households that had moved were composed of husband and wife or husband, wife, and children and relatively little difference existed with regard to type of place moved from.

\section{Services Satisfaction}

Satisfaction with services was closely related to migration (moving). This was examined by use of four variables - time when moved, geographic area moved from, reasons for moving, and type of place moved from. All were related to the State, and outside of Stat -fourth of the respondents said that they had "never moved." This group was the most satisfied with services. Although there was relatively little difference in satisfaction levels for the three groups that had moved, the analysis indicates the level of satisfaction tended to increase with the length of time since the last move.

The type of places moved from were categorized as farm, rural residence, small town, and urban. Those who had moved from farms tended to be the most satisfied, although those who had moved from urban areas also were more satisfied. The least satisfied had moved from rural non-farm residences.

Reasons for moving included to obtain employment, transferred by employer, preference for rural living, to change lifestyles, and dislike for the previous place. There were 22 services for which significant relationships were found. The most satisfied group typically were those that had moved as a result of being transferred, whereas the less satisfied groups tended to be those that disliked their previous residence and those that had moved to change lifestyles or to find employment.

\section{Conclusions}

Residents of rural areas in the nine counties surveyed are a relatively heterogenous group, as are the places where they live. The vast majority can be classified as rural non-farm residents. Relatively few depend on farming for all or most of their income although farming is an important activity for residents in a few of the counties. Many others produce vegetables, fruit, livestock, wood, and other products for home use. Many consider their places to be farms even though they produce no agricultural products for sale.

A substantial majority of the rural residents in all the counties (except for Jefferson) were born in the county where they now reside. Those who moved into the county tended to have been from outside the State. The rate of inmigration by those from out-of-state seems to have become more common in the last ten years before the survey, and especially so during the last five years.

The rural residents contacted in the survey represent a broad cross section with respect to their socio-economic characteristics. Housewives, students (mostly children), and retired persons accounted for a relatively large proportion of the household members, with the remainder in many different occupations of which no group was dominant. Although low household incomes were reported fairly frequently, intermediate income levels were more typical of the rural households included in the survey and a substantial number reported relatively high incomes. Educational levels among adults varied considerably, but there was a disproportionate number of persons with less than a complete high school education. Those with fewer years of formal schooling tended to be in the older age groups.

Several characteristics tended to vary with the location. Some notable variations were between the southern counties and those in other parts of the var. Webster County, which is in the central area, however, was more similar State. Webster county, which is in the central area, however, was more similar to the southern counties. Most of the southern counties are characterized by very rough terrain, that is, a large proportion of their land consists of steeply sloping hills with narrow valleys and ridges. Coal production is a major economic activity in all the southern counties (except for Lincoln) as well as in Webster and Upshur counties. They are adjacent counties, but vary substantially in the characteristics of their communities, residences, and

individuals.

Counties in the southern area, including Webster, tended to have much smaller average sizes of places, relatively few farms, produced fewer farm products, and had higher proportions of persons with less than a high school education. Their residents also tended to be less satisfied with the quality of public services than did persons in other areas of the State.

Income education, and household composition were important socioeconomic factors that were related to other characteristics or attitudes of the persons interviewed. Persons with higher incomes and more years of schooling tended to own more land. Lower income groups tended to be single person or two person (husband and wife) households who also were less formally educated. Generally, both those with higher and lower incomes were more satisfied with public services than those in intermediate income groups.

People who moved appeared to be different with respect to a number of characteristics. Those who had not moved were somewhat older, had more land, and tended to have higher incomes. They also were more satisfied with public services than those who had moved. Similarly, those who had moved more recently were less satisfied with services than those who had moved earlier, although the differences were not as striking as in the case of the movers vs nonmovers. Those who had moved from small towns or non-farm rural residences typically were less satisfied than those who had moved from farms or larger urban areas. 


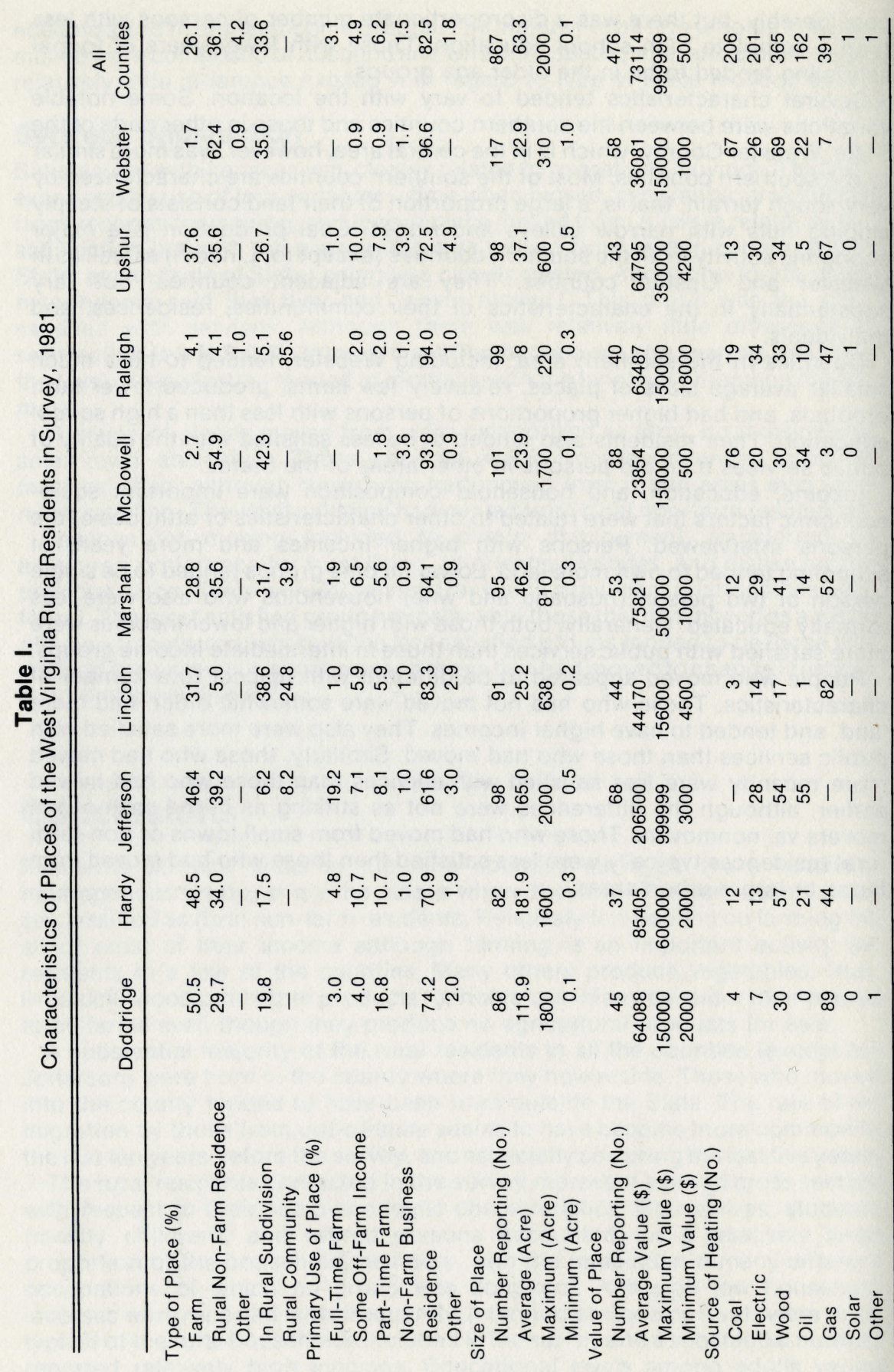

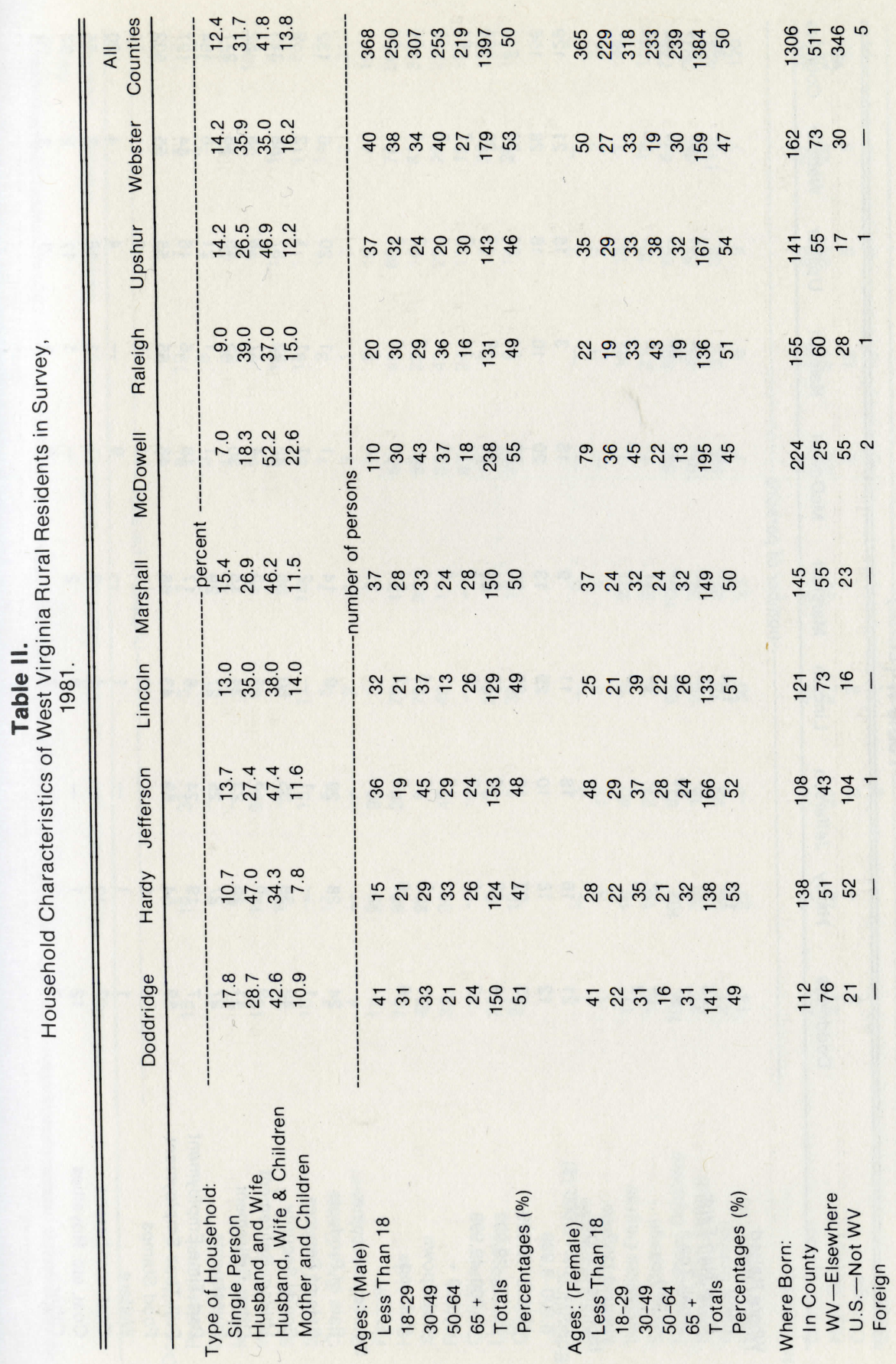

13 

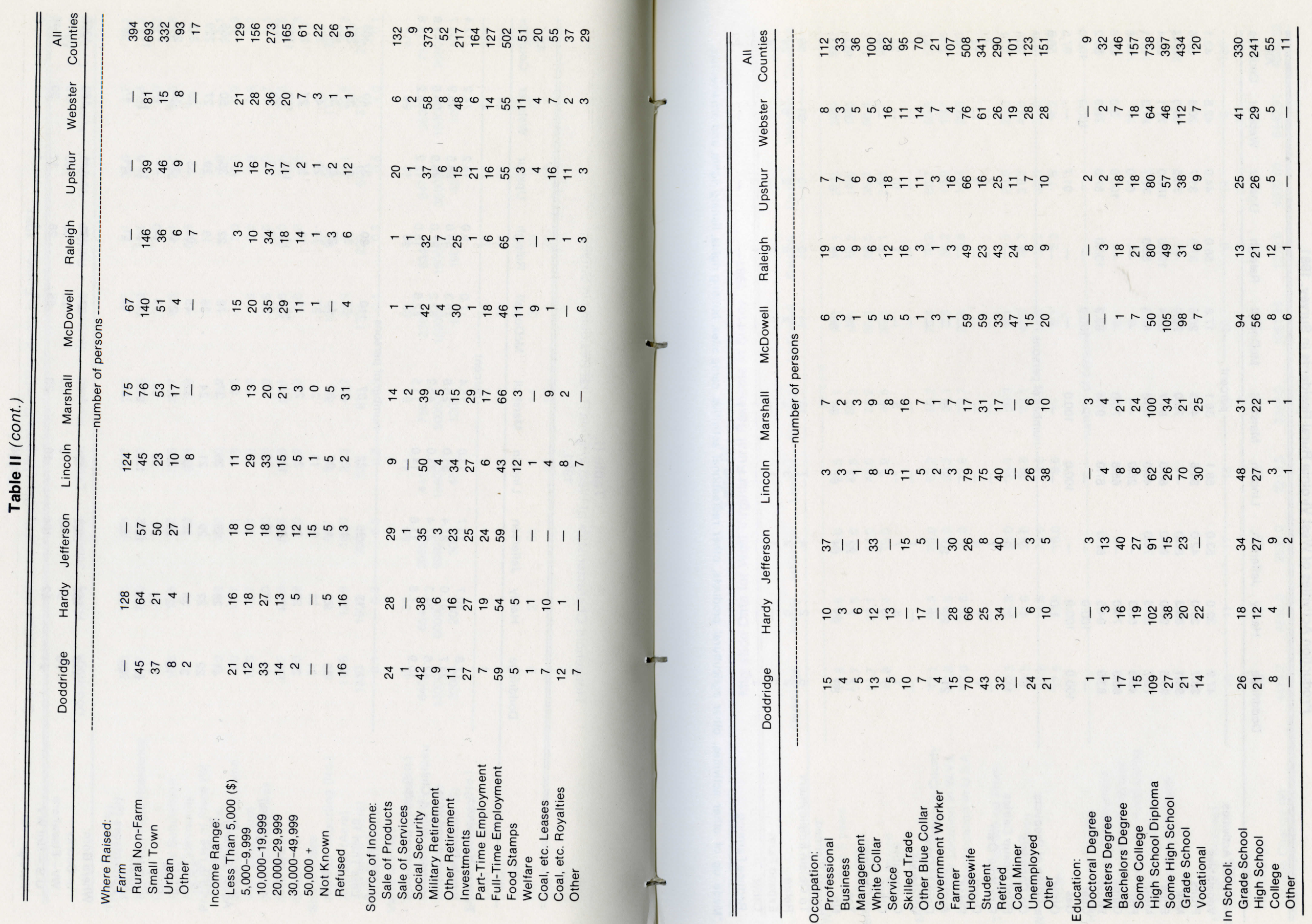

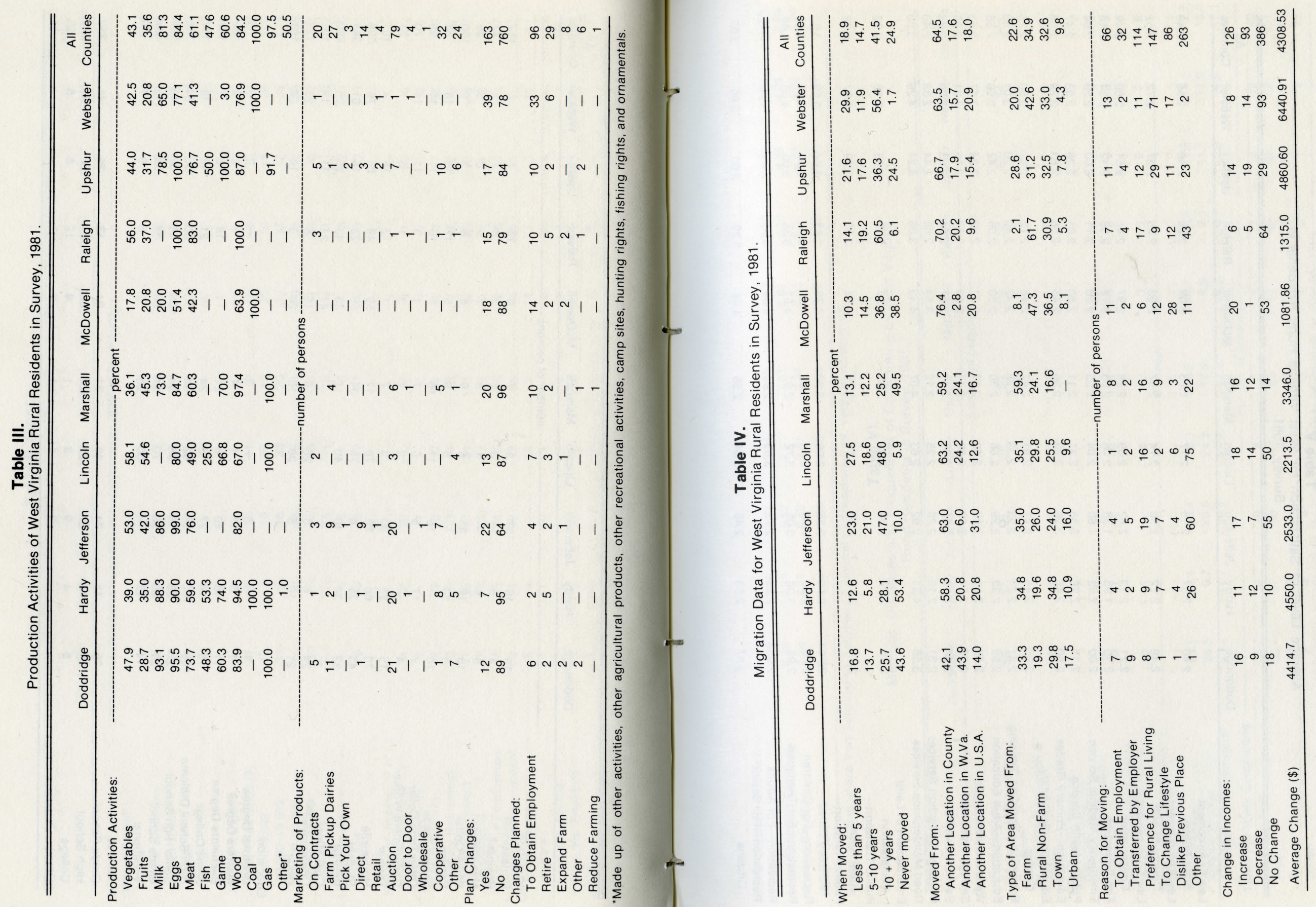

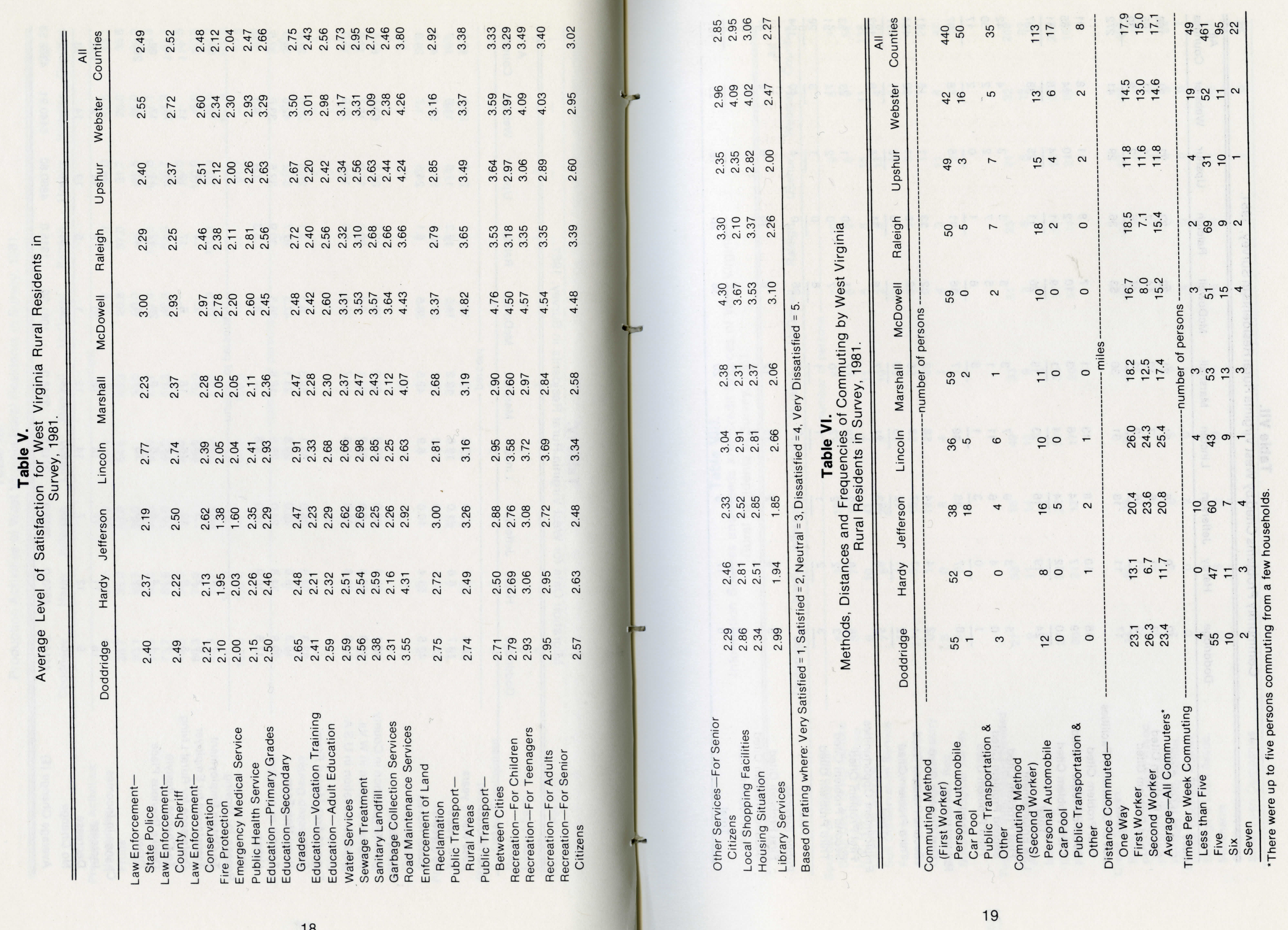

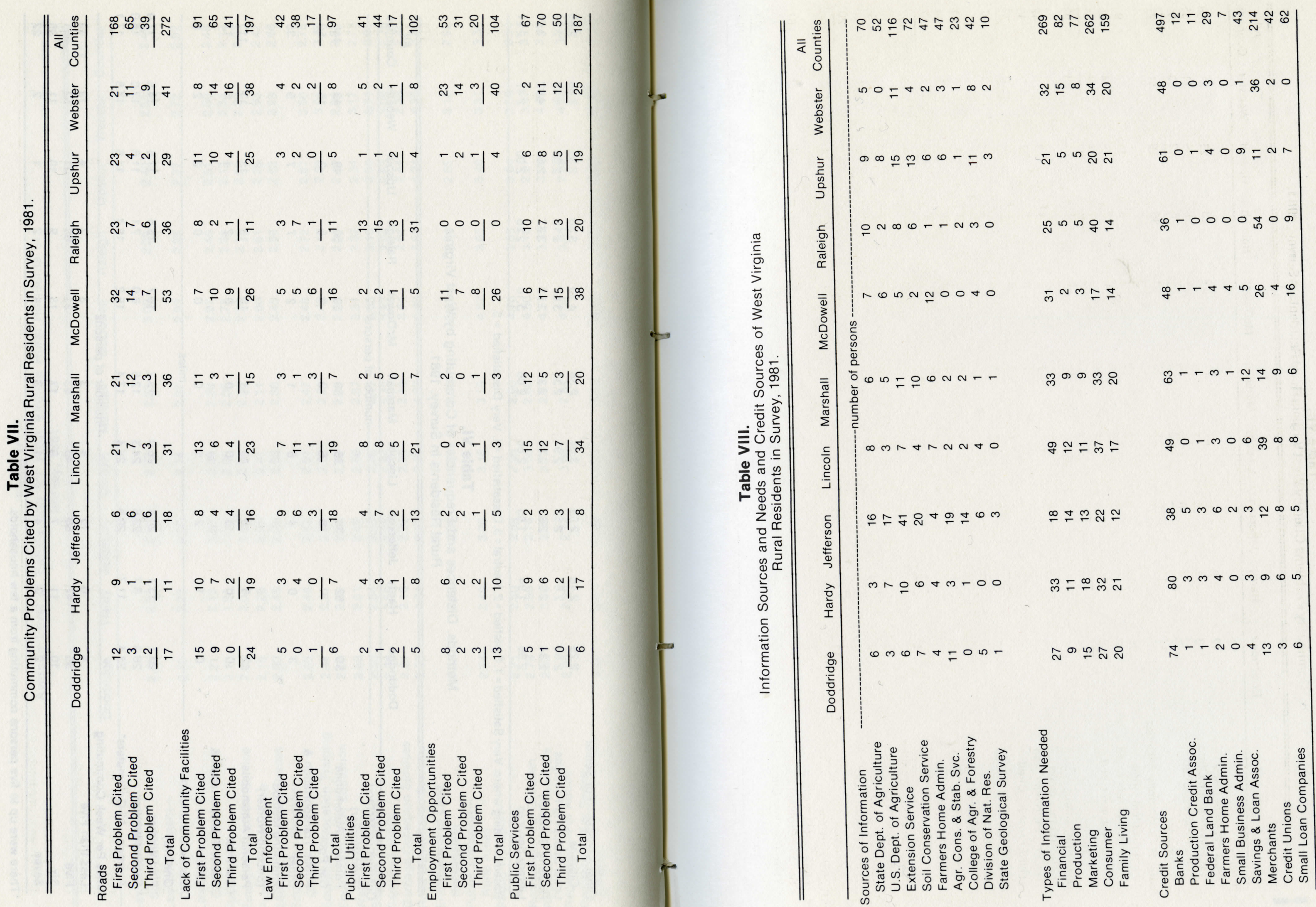